\title{
A TRACER STUDY OF A COHORT OF UNDERGRADUATE STUDENTS IN OUSL: PERCEIVED BENEFITS FROM PARTICIPATION IN DEGREE PROGRAMMES
}

\author{
G.D. Lekamge \\ Tamara Weerasinghe \\ Rohana Ratnayake \\ The Open University of Sri Lanka
}

\begin{abstract}
An exploratory study involving students enrolled in Law and Science degree programmers of The Open University of Sri Lanka (OUSL) was conducted to identify students' progression in the programmers, the perceived benefits in terms of occupational and social mobility, and economic returns, and any other non-pecuniary benefits. Especially developedquestionnaire was administered to a sample of students to get. their views on the benefits obtained. Results of this study unveiled crucial information of perceived and non-perceived benefits of the OUSL degree programmers. It could be observed that a substantial number of students have experienced a change in their employment and a huge increase in their income after completing the programs. Other interesting feature is that the number of students, who were in the lowest income level, had decreased substantially.
\end{abstract}

Key words: cohort study, degree programmes, economic return, occupational mobility, OUSL, social mobility, undergraduate students

The Open University is the only university in Sri Lanka that conducts Science, Law and Engineering undergraduate programme through distance mode. Normally the students enrolled in these programmes take a longer period than full time students to complete their studies. It was also noted that the drop out rates are high in these programmes when compared to similar programmes in conventional universities. However, it is argued that the effectiveness of a programme of study cannot be determined only on the basis of the number of graduates produced by a university. Students who have not yet completed the programmes may still have attained certain benefits from being in the programme.

Therefore, an exploratory study was conducted with students enrolled in Law and Science degree programmes in 1995 to identify their progression in the programmes, the perceived benefits in terms of occupational and social mobility and economic returns and any other non-pecuniary benefits. The data available at the university were analyzed to identify the patterns of their progression and a questionnaire was administered to a sample of students to get their views on the benefits obtained.

This study unveiled crucial information of perceived and non-perceived benefits of the OUSL degree programmes. It was also revealed that distance-learning methods enhance many skills of the students irrespective of their position in the programme and that they link up with higher public and personal image in the society, which ultimately benefited them with good economic returns by improving their family status and income. 
The main non-pecuniary benefits observed between these OUSL graduates were, they have better support from the programme to upgrade their knowledge and provide better opportunities in private sector, as the distance education methods help them to develop many skills that attract private sector opportunities. Many completers suggest that they can be easily compared with conventional university graduates but they feel they are more qualified in language, as they have followed lecturers in English medium.

\section{BACKGROUND TO THE PROBLEM}

The Open University of Sri Lanka (OUSL) which was established in 1980 is a national university constituted under the University Act No.16 of 1978 and the OUSL Ordinance No.1 of 1990 and has the same legal and academic status as any other national university in Sri Lanka. It is the only recognized university in Sri Lanka where students are able to pursue further education through distance education.

The academic programmes of the OUSL are specifically designed to enable persons aged 18 and above to pursue a higher education. The Programmes of the University enable students to join in at the level of the qualifications they possess and are structured from Foundation and Certificate levels and proceed to Diploma, Bachelors Degrees and Postgraduate Diplomas and higher degrees.

At present with a total student enrolment of around 20,000, OUSL caters to more than one-third of the total university student enrolment in the country. The students are enrolled in 32 programmes of study out of which 80 per cent of the students are employed and around 45 per cent are women. The completion of programmes by students become more difficult for students who enroll at Open Universities as they are compelled to study while working and attending to their normal family responsibilities. It is pertinent therefore, to examine the other benefits that will force the students to remain in the programme.

A number of studies have been conducted on different aspects of Open and Distance Learning at the OUSL. They indicate that there are high dropout/failure rates at different levels of different programmes. Especially those who are enrolled in the degree programmes take longer periods than expected to complete their studies. Therefore it is very difficult to evaluate a programme on the basis of completion and dropout rates. This study was directed to explore the benefits that the students will get by participating in two degree programmes of the Open University of Sri Lanka

\section{LITERATURE REVIEW}

During the last two decades, distance and open learning has recorded a rapid growth in most countries of the world, especially in developing countries. Open and Distance Learning are perceived as a more economical means of expanding and democratizing education. Breaking free of the shackles of physical infrastructure and internal staff resources as in a conventional system, Distance Education provides opportunities for sharing resources, for catering to a more geographically dispersed student clientele and for offering a wide range of programmes to suit the needs of a more heterogeneous group of customers. 
One popular indicator which has extensively been used by distance institutions to assess effectiveness is the completion/retention or persistence/drop out. Numerous studies have been carried out by distance educators to identify the characteristics of high risk students, reasons for dropping out from the programmes (Woodley \& Mcintosh ,1977, Phythan \& Clements , 1980,) and the nature of support needed by these students to reduce the tendency for dropping out (Thompson, 1997; Ismail, 1997). Many studies show that even in prestigious distance institutions pass rate is very low compared to conventional institutions. Those studies used different definitions for 'drop out' and 'success' based on the nature of the programme under study.

However, distance educators argue that it is not surprising that relatively few students complete distance delivered degree programmes. For a variety of reasons, a majority of students do not persist beyond the first course they take" (Shale \& Gomes, 1998). There are certain other weaknesses in using completion/retention as a measure of performance in the context of distance education. Due to open admission and flexible nature of distance courses, it would be very difficult to categorize persistent and drop out students. There is anecdotal information that some students say that they get as much as they want from a course without having to complete it formally (Shale \& Gomes, 1998). As they further reported, there are a large number of unofficial students who watch the television programmes and who may even write in to obtain course material prepared for the programme without registering in that programme. Therefore they argue that " completion/ retention is an indicator that potentially can be damaging to distance institutions" ( p. 10). They suggest several other indicators such as student satisfaction, employer satisfaction, employment indicator and financial indicator as alternatives to the above.

Further there is research evidence to support the idea that students select distance programmes due to limitations of on-campus programmes. For instance, Wallace (1996) conducted a study to investigate the nature of changes of demographic characteristics of students and the reasons for enrolling in distance education programmes. The largest number of additional responses came from students indicating that they considered independent study superior to the on-campus experience.

There is research evidence to support that many students are able to get economic benefits while continuing their study programmes even though some of them may decide to drop out from the programmes at a later stage. On the other hand, it is relevant to question whether distance higher education bestows only economic benefits on the recipients of this education. Access to university education, through whatever mode, provides opportunities for self-learning to supplement what is acquired through formal education and for social interaction. Especially for adult distance learners in open universities, such learning and interaction can open unlimited avenues for social relationships and acquisition of social skills. While economic benefits can accrue mostly to those who complete formal education and obtain diplomas and degrees, social benefits are within the reach of most of those who enroll in programmes and continue for even some time only.

\section{OBJECTIVES OF THE STUDY}

The main objectives of the study were three fold. They were to identify

(a) progression of enrollees in the Degree Programmes selected for the study

(b) perceived benefits in terms of occupational and social mobility and economic returns

(c) any other non-pecuniary benefits 


\section{SAMPLE OF THE STUDY}

The 1994/95 registered student population was considered as the cohort of under graduates for this study, as it was the first batch whose personal information was recorded under the electronic database system. The study was carried out using three different mechanisms, to fulfill the objectives of the study. The three mechanisms are given below.

(i) Institutional study with the help of the available data in the data base of the OUSL

(ii) Questionnaire based survey to identify any social, occupational or economical benefits for the participants

(iii) Focus group discussion to seek any non-pecuniary benefits in participating distance education programmes

A total of 1105 and 1794 students were registered in the BSc and Law programmes respectively for academic year 1994/95. This entire group was subjected to a computer analysis to find out the trends in the sample of students in terms of gender, centre, the pattern of getting eligibility/pass and the patterns of dropping/not completing the course. However, a proper institutional analysis could not be carried out due to non-availability of reliable and sufficient data with regard to the LLB programme.

\section{METHODOLOGY}

A sample of 500 and 557 students was randomly selected out of the registered students of the B Sc and LLB programmes respectively for the questionnaire survey and it represented roughly about one third of the total student population of that academic year. However, only 81 students from BSc and 107 students from Law porgramme had responded to the questionnaire.

The highest percentage of students who responded were females and were from the age group 1835 ( $98 \%$ B. Sc and $56 \%$ LLB). Only $14 \%$ of BSc students were married at the time of enrollment where as this percentage was $43 \%$ with regard to Law students (Table 9 ). This has changed at the time of completing the questionnaire to $54 \%$ (BSc) and to $79 \%$ (LLB).

A considerable number of Science students in the sample had $A / L$ qualifications and it is the minimum qualification required for enrolling in the BSc programme. However, $45 \%$ of Law students declared that they already had a degree while the percentage of respondents who had passed the G.C.E (Advanced Level) was 39\%.

In addition to questionnaire survey interviews are carried out to obtain data in order to examine other non- pecuniary benefits obtained by the students in participating in this degree programme. A schedule for the focus group interviews was prepared after identifying areas for further study by the research team.

\section{MAIN CONCLUSIONS FROM THE STUDY}

\section{a) Year wise completion/dropout}

The identification of patterns for year wise completion was possible only with regard to B.Sc programme. The highest number of students had managed to complete the programme in four years was $43 \%$. However it clearly indicates that the average time period required for a student, is 4-6 years to complete the B.Sc. degree programme (89\%) using distance-learning methods. A 
remarkable feature of the data is that a small number of students $(04 \%)$ have completed the degree within the lowest time period (in three years).

A very high drop out rate could be identified at Level $3(28 \%)$ compared to Level $4(08 \%)$ of the B.Sc programme.

\section{b) Position of the respondents in the two degree programmes}

The highest number of respondents were completers (80) and they were from the Colombo Centre (52). However, more than $22 \%$ had yet to complete and $32 \%$ had dropped out of the Law programme where as the continuing percentage for Law was 24 and 18 for the BSc programme. The dropout rate of Colombo Regional Centre was comparatively higher than that of other centres .

\section{c) Explanations for success and drop out}

For both groups of students the main factor contributing to programme completion was their 'own determination' (93.5\% and $89.6 \%)$.. The second highest preference was given to 'professional benefits' (42.2\% and $40.5 \%$ in the second rank) . It is not an unexpected response for open learning institutes where students come for a particular purpose at a particular time that they feel that they should have a certain qualification to survive in the competitive society.

\section{d) Contributory factors for continuation and discontinuation}

The majority of students who have not yet completed BSc and LLB programmes strongly felt that the main reason for their continuation is their 'own determination'. It was the same factor identified by the completers for their completion. 'Professional benefits' occupied the second highest place in the Law programme where as in the B. Sc programme 'course met my needs' emerged as the second reason. $41.7 \%$ respondents of the LLB programme had marked the same response as their third reason.

'Difficulty of combining study with employment' together with 'not sufficiently prepared' was stated as the main reasons for delaying the completion of the programmes. One fact may be that their courses of studies may not have direct relevance to their present employment. Secondly, this can be related to the fact that majority of distance learners are employed or tied up with family burdens.

Factors leading to discontinuation varied according to the programme and Table 1 shows the findings

Table 1. Factors for Discontinuation

\begin{tabular}{lcccccc}
\hline \multirow{2}{*}{ Statements } & \multicolumn{3}{c}{ BSc programme } & \multicolumn{3}{c}{ Law programme } \\
\cline { 2 - 7 } & $\begin{array}{c}\text { Rank 1 } \\
(\%)\end{array}$ & $\begin{array}{c}\text { Rank 2 } \\
(\%)\end{array}$ & $\begin{array}{c}\text { Rank 3 } \\
(\%)\end{array}$ & $\begin{array}{c}\text { Rank 1 } \\
(\%)\end{array}$ & $\begin{array}{c}\text { Rank 2 } \\
(\%)\end{array}$ & $\begin{array}{c}\text { Rank 3 } \\
(\%)\end{array}$ \\
\hline Family obligations forced me to interrupt study & 30.4 & 13.3 & 16.7 & 33.3 & 15.8 \\
Financial reasons forced me to interrupt study & 21.7 & 33.3 & 8.3 & 20 & 26.3 & \\
I could not combine study and employment & 21.7 & 20.0 & 8.3 & 20 & 15.8 & 50 \\
effectively & & & & & & \\
Support received at the centre is not sufficient & 4.3 & 13.3 & 16.7 & 3.3 & 5.3 & 16.7 \\
Course was too difficult & & 6.7 & & 3.3 & - & 16.7 \\
\hline
\end{tabular}


Both student groups rated 'family obligations' as the first reason for dropping out Table 3. A substantial number also identified financial reasons' as a reason for dropping out from both programmes. The data suggests that the 'average married employed students' find it difficult to meet the requirements of the programmes due to family obligations, financial reasons and the responsibilities at the work place which ultimately drive them to give up the course.

\section{e) Occupational Benefits}

Only a half of the BSc students were employed full time at the time of enrollment. However, at the end of the programme a substantial proportion (82\%) was employed full time.

At the time of enrollment, the majority of LLB respondents (80\%) were employed as many had a degree before enrolling in the programme and their percentage higher than that of their BSc counterparts (55\%). Therefore, only a slight change could be noted in their employment situation (from unemployed to employed). This situation could be linked with their expectations where many Law students had expected either an improvement in their knowledge or in their personalities ('improve self image' and 'improve public image') which might help them to secure their jobs as lawyers (Table 4).

'Improving knowledge' was the most popular expectation of BSc students though 'qualify for promotion', 'secure a job to match expectations' and 'achieve self -confidence were emerged as the second, third and fourth expectations. These types of expectations are natural with respect to open and distance degrees as the majority of students were those who could not enter conventional Universities due to various reasons.

Table 2. Expectations at Enrolment

\begin{tabular}{lll}
\hline \multicolumn{1}{c}{ Expectations } & BSc Percentages & LLB Percentage \\
\hline Improve Knowledge & $63.9(1)$ & $79.44(1)$ \\
Qualify for promotion & $41.0(2)$ & 20.56 \\
Secure a job to match expectations & $39.8(3)$ & 38.32 \\
Achieve self confidence & $36.1(4)$ & 32.71 \\
Widen experience in life & 34.9 & $47.66(2)$ \\
Enhance income level & 31.3 & 30.84 \\
Improve self image & 30.1 & $44.86(3)$ \\
Improve public image & 27.7 & $42.99(4)$ \\
Acquire knowledge \& training relevant to job & 27.7 & 30.84 \\
Making up for lost opportunities in past & 27.7 & 25.23 \\
Learn to study systematically & 19.3 & 17.76 \\
Develop a new carrier & 14.5 & 23.36 \\
\hline
\end{tabular}

Comparison of the percentages in Table 4 is indicative to some extent of the differences in the nature of the two programmes. The BSc degree is to a large extent on academic preparation for a job in any relevant field, whereas the Law degree essentially requires the development of certain personality attributes for the success and mobility of Lawyers. This is perhaps the explanation for the high percentage of that had selected 'widen experience in life' 'improve self -image' and 'improve public 
image'. Knowledge obtained from the programme had to be supplemented by experience as well as personal development.

However, an improvement of their employment status could be noted in all the categories (completers, non-completers and dropouts) of Law students. The unemployment had come to almost zero in the case of completers and non-completers. In the case of dropouts it had come down to $01 \%$. It was interesting to note that with regard to BSc students both completers and dropouts had experienced a change in their employment position.

\section{CHANGE IN THE NATURE OF EMPLOYMENT AND INCOME LEVEL}

The majority of respondents were engaged in teaching $(46.3 \% \mathrm{BSc}$ and $28.0 \% \mathrm{Law})$ at the time of enrolment (Table 3). Clerical (27\%) jobs emerged as the second highest in the B. Sc programme and Administrative /managerial jobs in the LLB programme.

Table 3. Occupation at Enrolment and Current

\begin{tabular}{lrrrr}
\hline & \multicolumn{2}{c}{ Occupation at enrolment \% } & \multicolumn{2}{c}{ Occupation current \% } \\
\cline { 2 - 5 } & BSc & LLB & BSc & LLB \\
\hline Professional & 2.4 & 11.2 & 0.1 & 26.2 \\
Managerial/Administrative & 2.4 & 20.6 & 12.7 & 26.2 \\
Teaching & 46.3 & 28.0 & 43.6 & 21.5 \\
Clerical/Secretarial & 27.0 & 9.3 & 20.0 & 3.7 \\
Technical & 12.2 & 0.9 & 7.3 & 2.8 \\
Health Associates & 2.4 & 0.9 & 3.6 & 0.9 \\
Sales & 4.9 & 0.9 & 1.8 & 0.9 \\
Security Forces & & 4.7 & & 0.9 \\
Skilled Construction & & 0.9 & & 3.7 \\
Agricultural,Fishing, Farming & & & 3.6 & \\
Driver & & 0.9 & & 0.9 \\
Other & 4.9 & 3.7 & 7.3 & 5.6 \\
System missing & & 17.8 & & 6.5 \\
\hline
\end{tabular}

Even though there was no significant change in the employment position (employed and unemployed) of Law students a significant change in the nature of employment could be observed. Professional occupations, which occupied third position at enrolment, came to number one position at completion. Teaching profession, which was highest at enrolment, occupied third place at completion. After completion of the programme the situation remained unchanged for B. Sc students as $44 \%$ are employed as teachers and $20 \%$ in the clerical service. Even though they are the top-most categories of employment, a drop was shown in the number employed after completing the programme as compared to enrollment. However there was a marked increase in managerial administrative level positions, which suggests a more than five fold increase in this category.

The majority of respondents in both programmes had an income lower than Rs. 10,000 at the time of enrolment. After completing the programme a substantial number of students had improved their income level up to Rs.5000 to 10,000 or up to Rs. $10,000-20,000$. It was interesting to note that at 
enrolment only 10 students in the Law programme had an income above 20,000 though the number has increased up to 23 at current, which included three BSc students as well.

Table 4. Income Levels of Respondents - At Enrolment and Current

\begin{tabular}{|c|c|c|c|c|}
\hline \multirow{2}{*}{ Income level Rs } & \multicolumn{2}{|c|}{ Enrolment } & \multicolumn{2}{|c|}{ Current } \\
\hline & BSc & LLB & BSc & Law \\
\hline Less than 2500 & $11(25 \%)$ & 8 (8.5\%) & $1(1.6 \%)$ & \\
\hline $2501-5000$ & $18 \quad(40.9 \%)$ & $25(26.5 \%)$ & $7(11.8 \%)$ & 1 (.9\%) \\
\hline $5001-10000$ & 13 (29.5\%) & $36 \quad(36.2 \%)$ & $38(64.4 \%)$ & $34(32.7 \%)$ \\
\hline $10001-20000$ & 2 (4.6\%) & 15 (15.9\%) & $10(18.8 \%)$ & $46(44.2 \%)$ \\
\hline 20001-40000 & & $9(9.5 \%)$ & $2(3.3 \%)$ & $17(16.3 \%)$ \\
\hline Over 40000 & & $1(1.1 \%)$ & $1(1.6 \%)$ & $6(5.8 \%)$ \\
\hline Total & 44 & 94 & 59 & 104 \\
\hline
\end{tabular}

Irrespective of the category they belonged to, many students had experienced a change in their income level.

\section{OTHER NON-PECUNIARY BENEFITS}

\section{Achievements}

Both categories of students ( $85 \%$ LLB \& 59\% B. Sc) had improved their knowledge after following the degree programmes. Other four main achievements they had identified according to the priority order were, Improving self-confidence (45\% \& 30\%), Improving their public image(44\% \& $28 \%$ ); Widening experience(44 \& 27\%); and improving the self image (44 \& $25 \%$ ).

The next highest achievements were qualifying for promotions $(20 \%)$ and learning to study systematically $(20 \%)$ for B. Sc students and make up for lost opportunities $(29 \%)$ and acquiring knowledge ( $25 \%$ ) for LLB students .

\section{Personality Changes}

The majority of B. Sc students have stated their 'become more responsible' and 'developing new interests' as the two top most changes in their image LLB students had changed to a great extent in 'acquiring new goals' and 'developing new academic interests' . In both programmes, a substantial number had agreed that they experienced the following changes in their personalities to some extent; 'acquired new goals' (B. Sc ), 'a satisfied the social life' (B. Sc and Law) 'able to communicate better' (B. Sc and Law), 'tolerant of other peoples views' (B. Sc and Law), 'develop academic interests' (B. Sc), 'develop extracurricular interests' (B. Sc) and 'becoming matured' (Law).

\section{Acquisition of Skills}

Out of the six skills listed in the questionnaire, the majority of BSc students listed 'communication skills' and Law students listed 'knowledge' as their greatly improved skill. However, B. Sc and Law students had given a similar rating to 'communication skills' and 'rationality skills' respectively. B. Sc students rated ' knowledge' , 'Numerical skills' .'Rationality and interpersonal skills' as the moderately improved skills For LLB students they were 'interpersonal skills ', 'Rationality skills' and Leadership skills. This is understandable, as the Law programme is not directed towards improving numerical skills of its students. An improvement in rational skills i.e. ability to reason out 
independently and logically is, on the other hand, a skill on which the programme throughout its four year course is directed.

At the focus group interviews the completers of the Law programme expressed that they are able to think rationally before a decision is taken and also to adopt a somewhat tolerant attitude towards problems they face without reacting inflexibly towards them. Further it was revealed that OUSL students have better English language skills than the graduates who study in conventional universities in the Sinhala medium.

\section{Recognition Given to OUSL programmes}

Thirty five percent of B. Sc students and $60 \%$ LLB students marked their programme as a programme which gains equal recognition as any equivalent degree programme in conventional universities. It was encouraging to note that with a considerable number of LLB and B. Sc students had given more recognition to the respective OUSL programmes than the other programmes (Figure $9 \& 10$ ) Focus group interviews also revealed that the attitude of their neighbors, friends, colleagues and relatives towards them have changed and that now they are treated with respect by the people who around them.

\section{CONCLUSION}

This study unveiled crucial information of perceived and non-perceived benefits of the OUSL degree programmes. It could be observed that a substantial number of students have experienced a change in their employment and a huge increase in their income after completing the programme. The other interesting feature is that the number of students, who were in the lowest income level, had decreased substantially.

With the completion of the two degree programmes OUSL students had gained many skills, especially they had managed to enhance their knowledge. More than fifty percent of the students have identified that they had improved numerical (B. Sc only), communicational, rational and interpersonal skills. This had facilitated them in improving their self and pubic images. Further more society, they pointed out, has an equal recognition to the OUSL programme with the other Degree Programme in conventional universities.

The main non-pecuniary benefits observed between these OUSL graduates were, they have better support from the programme to upgrade their knowledge and provide better opportunities in private sector, as the distance education methods help them to develop many skills that attract private sector opportunities. Many completers suggest that they can be easily compared with conventional university graduates but they feel that they are more qualified in language, as they have followed lecturers in English medium.

\section{ACKNOWLEDGEMENTS}

I would like to acknowledge the advice and guidance received from Ms. Reehana Raza, the Principal Researcher of the project and also the financial assistance received from the International Research Foundation of Open Learning. 


\section{REFERENCES}

Howell, S., Williams, P.B., \& Lindsay, N.K. Thirty-two trends affecting distance education: An informal foundation for strategic planning. http//www.westga.edu/-distance /ydla/fall63/howell63.html

Kember, D. (1987). Approaches to studying research and its implecations for the quality of learning from distance education. Journal of Distance Education. http//cade.athabascau.ca/vol2.28_Kember_and_Harper.himl

Lekamge, G.D. (1993). Factors affecting success of distance education teacher training programmes. Unpublished Ph D dissertation OUUK.

Lekamge, G.D. \& Karunanyake, S.P. (2003). Factors affecting the completion of Master of Education Programme. Faculty Annual Sessions.

Powell, R., Conway, C., \& Ross, L. (1990). Effects of student predisposing characteristics on student success. Journal of Distance Education, Vol 15.1.

Rockwell, K., Furgason, J., \& Mars, D.B. Research and evaluation needs for distance education. A Delphi Study. Journal Series No 13083. Agricultural Research Division, University of Nebraska.

Scalese, E.R. Attrition and persistence in distance education college programs.

Thompson, E. (1997). Distance education drop-out: What can we do? Teaching and learning forum. http/lsn.curtin.edu.au/1997/thompson.html

Senaratne, de Costa \& Bandara. (2001). A survey of graduates of the Open university of Sri Lanka. OUSL Journal Vol. 3.

Shale, D. \& Gomes, J (1998). Performance indicators and university distance education providers. Journal of Distance Education. http://wwwestga.edu/-distance/ojdla/fall/33/rockwell33.html

Wallace, L. (1996). Changes in the demographics and motivations of distance education students. Journal of Distance Education, Vol.11.1.

Zarookdeen. (2004). Student perception on PGDE print material with reference to Tamil medium. Unpublished M.Ed dissertation. 